\title{
Data mining of digitized health records in a resource-constrained setting reveals that timely immunophenotyping is associated with improved breast cancer outcomes
}

Arturo López-Pineda ${ }^{1 *+} \mathbb{D}$, Mario F Rodríguez-Moran ${ }^{2+} \mathbb{D}$, Cleto Álvarez-Aguilar ${ }^{2,3}$ (D), Sarah M Fuentes Valle ${ }^{4}$, Román Acosta-Rosales ${ }^{5}$, Ami S Bhatt ${ }^{6,7}$ (D), Shruti N Sheth ${ }^{8}$ and Carlos D Bustamante ${ }^{1,6}$ (D)

\begin{abstract}
Background: Organizations that issue guidance on breast cancer recommend the use of immunohistochemistry $(\mathrm{IHC})$ for providing appropriate and precise care. However, little focus has been directed to the identification of maximum allowable turnaround times for $\mathrm{IHC}$, which is necessary given the diversity of hospital settings in the world. Much less effort has been committed to the development of digital tools that allow hospital administrators to monitor service utilization histories of their patients.
\end{abstract}

Methods: In this retrospective cohort study, we reviewed electronic and paper medical records of all suspected breast cancer patients treated at one secondary-care hospital of the Mexican Institute of Social Security (IMSS), located in western Mexico. We then followed three years of medical history of those patients with IHC testing.

Results: In 2014, there were 402 breast cancer patients, of which 30 (7.4\% of total) were tested for some IHC biomarker (ER, PR, HER2). The subtyping allowed doctors to adjust (56.7\%) or confirm (43.3\%) the initial therapeutic regimen. The average turnaround time was 56 days. Opportune IHC testing was found to be beneficial when it was available before or during the first rounds of chemotherapy.

Conclusions: The use of data mining tools applied to health record data revealed that there is an association between timely immunohistochemistry and improved outcomes in breast cancer patients. Based on this finding, inclusion of turnaround time in clinical guidelines is recommended. As much of the health data in the country becomes digitized, our visualization tools allow a digital dashboard of the hospital service utilization histories.

Keywords: Breast neoplasms, Immunohistochemistry, Tumor biomarkers, Medical records, Clinical coding, Data mining, Mexico

\section{Background}

In breast cancer, immunohistochemistry (IHC) is a critical part of the accepted standard of care for determining prognosis and response to therapy. A panel of three IHC markers-estrogen receptor (ER), progesterone receptor (PR), and human epidermal growth factor receptor 2 (HER2) - are the most commonly used due to its

\footnotetext{
* Correspondence: arturolp@stanford.edu

${ }^{+}$Arturo López-Pineda and Mario F Rodríguez-Moran contributed equally to this work.

'Department of Biomedical Data Science, School of Medicine, Stanford University, 1265 Welch Road, Stanford, California 94305, USA

Full list of author information is available at the end of the article
}

predictive value for chemotherapy response in breast cancer [1]. Despite the existence of other IHC markers (e.g. Ki67, p53) [2], and the development of several commercial multi-gene tests that improve prognosis and treatment selection [3], the availability and expense of these tests remain largely prohibitive for constrain-resourced hospital settings, regardless of country income.

Mexico is an emerging country with an upper-middle income economy (as considered by the World Bank), where the healthcare system still has challenges procuring enough resources. The Mexican consensus [4] and clinical practice guidelines for breast cancer [5-7], the

(c) The Author(s). 2018 Open Access This article is distributed under the terms of the Creative Commons Attribution 4.0 International License (http://creativecommons.org/licenses/by/4.0/), which permits unrestricted use, distribution, and reproduction in any medium, provided you give appropriate credit to the original author(s) and the source, provide a link to the Creative Commons license, and indicate if changes were made. The Creative Commons Public Domain Dedication waiver (http://creativecommons.org/publicdomain/zero/1.0/) applies to the data made available in this article, unless otherwise stated. 
main working documents for oncologists in the country, recommend routine use of a 3-marker panel (ER, PR, HER2) to guide management and treatment for patients. In Mexico, estimating the nationwide frequencies of molecular status is a challenging task due to the absence of cancer registries. However, two recent cohort studies in Mexico City [8, 9] showed that $56-64 \%$ of tumors had positive hormone receptor (ER, PR) status; $16-20 \%$ had HER2 positive status; and $23-26 \%$ had triple negative status. While these frequencies mirror those of other high and middle income countries, there is a troubling onset of disease among younger patients in Mexico (aged <40), with a high prevalence of triple-negative breast cancers [10]. Furthermore, there is an increased mortality trend associated with breast cancer in the country [11]. Timely testing for these IHC biomarkers needs to be fully recognized in clinical guidelines and hospital policies, and the testing must account for the wide diversity of patient trajectories and hospital settings [12].

Recently, organizations that issue guidance on breast cancer care worldwide have been broadening their focus to include resource-stratified guidelines, which reflects the diversity of hospital settings in the world:

- The Breast Health Global Initiative (BHGI) guideline for breast cancer healthcare in low-income and middle-income countries [13] offers four levels of guidance: basic (hormone receptor status by empiric assessment or response to treatment); limited (determination of ER status by IHC); enhanced (determination of PR status by IHC and measurement of HER2 overexpression); and maximal (gene profiling testing).

- The National Comprehensive Cancer Network (NCCN) framework for oncology care resourcestratification [14] offers four levels of guidance equivalent to those in the BHGI guideline.

- The American Society for Clinical Oncology (ASCO) offers a resource-stratified guideline for cervical cancer [15], which can be used to illustrate the need for a similar guideline for breast cancer.

- The World Health Organization (WHO) [16] offers guidance to countries on three resource scenarios (low, medium, high) with differential actions in the national cancer control programs, but has not yet offered a breast cancer specific resource-stratified guideline.

In this study, we aimed to quantify the potential effect that timely $\mathrm{IHC}$ testing has in improving patient outcomes. We hypothesized that with the use of data mining on digitized hospital records it is possible to facilitate the quantification of IHC testing as well as other services offered to breast cancer patients. At the same time, this study provided hospital administrators with a visual monitoring tool that facilitates the burden of human-intensive labor to quantify critical procedures in resource-constrained hospitals (including IHC testing).

\section{Methods \\ Hospital setting}

The Mexican Institute of Social Security is a hybrid single-payer system with an integrated network of hospitals nationwide. In Michoacan (a state located in western Mexico), the General Regional Hospital No. 1 (HGR1) is the designated secondary-care facility for the IMSS-insured population, estimated at $1,288,695$ people ( $28 \%$ of the state's population), according to the 2015 census [17]; of these, 202,547 are women with ages between 40 to 69 years, which correspond to the target group for mammography screening for breast cancer. While there is a lot of heterogeneity between states in Mexico, it is important to highlight that the state of Michoacan ranks 29 out of 32 states in terms of competitiveness, governmental efficiency, and overall wealth [18].

The HGR1 hospital is located in a suburban community adjacent to Morelia (the capital of Michoacan). HGR1 is the secondary-care facility that serves as reference for seven General Zone Hospitals and 45 Family Medicine Units within the state of Michoacan. HGR1 has an oncology unit with a full complement of fixed staff and facilities available to all patients. It also offers pathology services, diagnostic imaging, and therapeutic capabilities with access to all approved drugs. Patients with breast cancer who require chemotherapy are sent to the outpatient medical unit, and patients with breast cancer who require radiation therapy are provided the service through an outsourced private service in the same city. The personnel include gynecologists, medical oncologists, surgical oncologists with significant breast cancer training, adequate numbers of nursing and pharmacy staff, surgeons with significant training, and cancer pathologists.

\section{Patients}

The study population for this research was all cumulative breast cancer patients seen in 2014 by medical staff at HGR1, as reported by the institution's breast cancer census in the absence of a cancer registry. To avoid selection bias in our study, we did not restrict the selection of patients to members of the female sex or any age group.

The general process at IMSS for breast cancer diagnosis is as follows. A patient with suspected breast cancer is referred from a primary-care facility to HGR1 after being examined by his/her family physician. If the physician suspects the existence of a breast lesion, the patient undergoes an imaging assessment using the breast imaging-reporting and data system (BIRADS) score. Upon arriving at HGR1, the patient is either seen by the breast cancer clinic (patients with BIRADS score 
0 and 3) for further imaging studies and/or fine-needle biopsy assessments, or directly referred to the medical oncology service (patients with BIRADS score 4, 5 and 6), at which point they undergo surgical biopsies for pathology analysis. The gold-standard diagnosis of breast cancer is then provided by a board-certified pathologist, who assigns one of the C50 codes (malignant neoplasms of breast) from the international classification of diseases version 10 (ICD 10).

The final inclusion criteria were those whose biopsies had been tested with IHC to detect ER, PR, HER2 antibodies; then. We reviewed the medical records (both electronic and paper) of all breast cancer patients at HGR1, selected only those with IHC testing, and followed their medical histories, ending with March 2017, making note of multiple medical visits to the breast cancer clinic, medical oncology service, and/or surgical oncology service. From their medical records, we extracted information about IHC testing (antibody ordered, date of ordering, date of results being obtained), chemotherapy and hormonal drugs administered, and radiation sessions and surgical procedures undertaken.

\section{Study design}

This was a retrospective hospital-based cohort study, using medical records collected routinely as part of clinical care. The objective was to understand the therapeutic impact on breast cancer patients of the time taken to test immunohistochemistry biomarkers in a resource-constrained hospital in western Mexico. We built a digital monitoring tool to report the frequency of treatment selection or treatment adjustment frequencies depending on breast cancer subtyping and the turnaround times for immunohistochemistry biomarker testing. The STROBE checklist is provided in Additional file 1 . All analyses were performed in $\mathrm{R}$ version 3.3.2.

\section{Patient trajectory monitoring}

We explored the paper- and electronic-based medical records for all patients with IHC testing, from the patient's first day at the hospital to the last follow-up pertaining to this study (occurring before March 2017). First, author MFRM manually reviewed the patient's medical records and curated a set of possible events experienced by the patients of this study, annotating the time points for each event for each patient. Then, author ALP annotated those events with standardized coding from the Unified Medical Language System (UMLS). When disagreement occurred, both authors discussed the translation to assign a UMLS code to the medical records in Spanish. Finally, similar events were grouped in top-level categories. The UMLS codes, UMLS descriptions, Spanish description, and the top-level categories can be seen in Table 1.

\section{Missing data}

Missing data was assumed to be non-missing at random (NMAR), and the events from Table 1 were considered missing for a specific reason. For example, if the code C2186775 (request lab result from MRI) was missing from a patient's medical record, we left that value unassigned, since it was assumed that an MRI was not requested for that patient. There is a small chance that this assumption might be violated (and introduce some bias) if the physician did request the exam/procedure but forgot to write it down in the medical record. However, we did not impute any missing data, since that might be a larger source of bias for this EHR-based data.

\section{Outliers}

We assessed the time-to-event distribution for each event in Table 1, and reported the distribution of the patient cohort in violin plots that included: the median turnaround time, the interquartile probability density estimation, and the 95\% confidence interval (whiskers). Outliers were identified using the 1.5 interquartile rule, but were not removed from the downstream analysis due to scarcity of data.

\section{Clustering}

We searched for groups of patients that had similar journeys in their hospital care. More technical details about the hierarchical clustering method are shown in Additional file 2. The input was a matrix of the number of days when events from Table 1 occurred for every patient, relative to their initial day of diagnosis in the hospital (day 0). Given that missing events were considered to be not missing at random (NMAR), they were filled with a large negative value (-1000 for this cohort). Then, a patient similarity distance was calculated using Euclidean distance between these time-to-event values for every pair of patients. An agglomerative hierarchical clustering was constructed using complete linkage, the distance between the two furthest points in two clusters. The selection of the appropriate number of clusters was done through cluster stability analysis.

\section{Results}

Our data mining efforts revealed the epidemiological information pertaining to this IMSS hospital as shown in Table 2. In this cohort, all patients were female. The highest prevalence of cancer was within the 50 to 59 year-old age group. There were 207 patients (51\%) diagnosed with early stages of cancer (stages I and II). Only 30 patients (7\%) had undergone estimated subtyping with IHC testing. Of all patients, 18 patients (4\%) were younger than 40 years old. At this hospital, 23 patients $(6 \%)$ had a BIRADS score of 2 or lower, meaning they should not have been sent to the secondary care 
Table 1 List of medical events with UMLS codes and descriptions in English and Spanish

\begin{tabular}{ll}
\hline UMLS code & UMLS description \\
\hline Visit & Clinic Visits \\
C2153644 & Visit for: gynecological exam \\
Oncology & \\
C1620996 & $\begin{array}{l}\text { Oncology; primary focus of visit; work-up, } \\
\text { evaluation, or staging at the time of cance } \\
\text { diagnosis or recurrence }\end{array}$ \\
C1617848 & $\begin{array}{l}\text { Oncology; primary focus of visit; expectant } \\
\text { management of patient with evidence of } \\
\text { cancer for whom no cancer- directed } \\
\text { therapy is being administered or arranged } \\
\text { at present }\end{array}$
\end{tabular}
Description in Spanish

Request lab

C2186763

C2186756

C2186777

C2186774

C2186775

Biopsy / Pathology

C0177666

C0585992

C0807321

Chemotherapy

C0086965

C4302504

Surgery / Radiation

C0436382

C0024881

C0851238

$\mathrm{IHC}$ results

C3248285

C3248286

Treatment adjusted

$\begin{array}{ll}\text { C1627778 } & \text { Treatment adjusted per protocol } \\ \text { C0419989 } & \text { Hormone replacement therapy started }\end{array}$

Adverse events

C0019993
Request lab results from pathology

Request lab results from hematology

Request lab results from $x$-ray

Request lab results from $\mathrm{CT}$

Request lab results from MRI

Needle biopsy of breast

Surgical biopsy of breast

Pathology report

Selection for Treatment

Chemotherapy started

Radiotherapy started

Mastectomy

Lumpectomy of breast

Quantitative HER2 immunohistochemistry $(\mathrm{IHC})$ evaluation of breast cancer consistent with the scoring system defined in the ASCO/CAP guidelines (PATH)

Quantitative non-HER2 immunohistochemistry $(\mathrm{IHC})$ evaluation of breast cancer (eg, testing for estrogen or progesterone receptors [ER/PR]) performed (PATH)

Hormone replacement therapy started

Hospitalization
Atención inicial en la unidad de medicina familiar (primer nivel de atención).

Atención inicial en la consulta de ginecología (segundo nivel de atención).

Atención inicial en la consulta de oncología médica.

Atención subsecuente en la consulta de oncología médica.

Solicitud de estudios de patología.

Solicitud de estudios básicos de laboratorio clínico.

Solicitud de estudios de imagen (tele de tórax, ultrasonido, mastografía).

Realización de estudios especiales de imagen (tomografía).

Realización de estudios especiales de imagen (resonancia magnética).

Realización de biopsia con aguja fina o gruesa

Realización de biopsia por escisión quirúrgica.

Reporte de estudio histopatológico.

Selección de tipo de tratamiento (quimioterapia, radioterapia, cirugía).

Inicio de quimioterapia.

Inicio de radioterapia.

Realización de mastectomía radical.

Realización de lumpectomía

Solicitud de estudios de inmunohistoquímica (Receptor de HER2).

Solicitud de estudios de inmunohistoquímica (Receptores de estrógeno y progesterona).

Ajuste de tratamiento de primera línea (posterior al primer ciclo de quimioterapia).

Inicio de tratamiento de reemplazo hormonal.

Complicación de proceso oncológico (internamiento a causa de cáncer) 
Table 1 List of medical events with UMLS codes and descriptions in English and Spanish (Continued)

\begin{tabular}{cll}
\hline UMLS code & UMLS description & Description in Spanish \\
\hline C1282471 & Local recurrence of malignant tumor of breast & $\begin{array}{l}\text { Recaída de proceso oncológico (mismo sitio tumor } \\
\text { primario). Recidiva local de tumor maligno de mama. }\end{array}$ \\
C3694291 & Metastasis from malignant neoplasm of breast & Reconocimiento de metástasis (tumor secundario). \\
C13065577 & Death (finding) & Fallecimiento / Muerte \\
Remission & & \\
C0687702 & Cancer Remission & Evolución favorable de paciente, mejoría clínica; remisión. \\
\hline
\end{tabular}

facility. In these cases, patients had external biopsy investigations in non-IMSS hospitals (usually private) and decided to continue their care for follow-up treatment at the IMSS oncology services.

\section{Digital monitoring}

Patient trajectories were finely segmented as shown in Fig. 1, which further allow digital analysis (and therefore optimization). Each patient is represented in a panel (rectangle) with colored bars, indicating the events that a patient experienced in the IMSS hospital. Each row represents one year of follow-up treatment for that patient, which can be from one to four rows (because the time maximum follow-up time span was three years and five months). The length of each colored bar represents the time between the occurrence of an event and the event that preceded it. Although events do not occur continuously, but, rather, happen at single time points (e.g. a patient visit, obtaining the results of a radiograph), the visual representation shown in Fig. 1 provides a sense of how much time was required for each event to occur, assuming nothing else happened at the same time.

\section{Turnaround time}

Further data mining on this cohort identified the turnaround time for IHC testing as shown in Fig. 2. Only 20 patients had information in their medical records relating to the timing of IHC testing. Although this service is referred to in the IMSS medical records, it is subcontracted to a private laboratory. There was large variation surrounding two key variables: a) the time needed to request a result, with an average time of 117 days (95\% C.I. 80-154 days; and the turnaround time needed to obtain the results, with an average time of 56 days (95\% C.I. 36-77 days). The total time to obtain a result from initial diagnosis was 173 days (95\% C.I. 131-216 days). Overall, for these 30 patients with IHC testing, 17 patients $(56.7 \%)$ had their treatments adjusted, and 13 patients $(43.3 \%)$ had their treatments confirmed.

\section{Discussion}

In Mexico, breast cancer continues to be a public health concern, even though more and more research is being done on its genomic changes and characteristics. Although our study investigated a small cohort of patients, the epidemiological characteristics among our cohort is similar to what has previously been estimated for the country (in regards to age group and staging) [11]. Our study further investigates the use of digital health mining tools for evaluating the timeliness of IHC testing, and the percentage of patients being tested. This tool can then be used to inform hospital administrators and public health officials.

\section{On the therapeutic value of IHC testing}

Despite the small number of patients with IHC, the results suggest usefulness of the IHC in therapeutic decision-making and in determining the prognosis of the patient. In the hospital included in this study, therapeutic decisions are made based on clinical, surgical and histological results such as physical appearance, tumor size, lymphatic invasion, tumor necrosis, histological type, degree of differentiation and the number of affected lymph nodes. This study supports the therapeutic importance of immunophenotyping (the use of IHC testing for subtyping of cancer patients), as has been demonstrated broadly in other studies focusing on populations in high income settings. These results should be carefully considered and addressed in treatment plans created by the multidisciplinary care team. With the incorporation of information about receptor status, the traditional (FEC) chemotherapy regimen recommended by the IMSS protocol, composed by 5-fluorouracil, epirubicin, and cyclophosphamide, can be adjusted to improve treatment outcomes.

Patients with estrogen positive $(\mathrm{ER}+)$ and/or progesterone positive $(\mathrm{PR}+)$ could benefit from anti-hormone or endocrine therapy to prevent recurrence, either aromatase inhibitors to block estrogen production (e.g. anastrozole, letrozole, or exemestane), or the selective estrogen receptor modulators (SERMs), which interfere with the ability of estrogen to stimulate the growth of breast cells (e.g. tamoxifene or toremifene).

Additionally, patients with HER2 positive (HER2+), in which tumors tend to grow and spread more aggressively, could benefit from a targeted therapy that could 
Table 2 Clinical characteristics of the cohort and receptor status for patients with $\mathrm{HC}$ testing

\begin{tabular}{|c|c|c|}
\hline Characteristic & Total (\%) & With $\mathrm{IHC}$ testing (\%) \\
\hline Overall & $N=402$ & $N=30$ \\
\hline \multicolumn{3}{|l|}{ Sex } \\
\hline Female & $402(100 \%)$ & $30(100 \%)$ \\
\hline Male & 0 & 0 \\
\hline \multicolumn{3}{|l|}{ Age at diagnosis } \\
\hline$<40$ & $18(4 \%)$ & $3(10 \%)$ \\
\hline $40-49$ & $62(15 \%)$ & $16(53 \%)$ \\
\hline $50-59$ & $174(43 \%)$ & $7(23 \%)$ \\
\hline $60-69$ & $127(32 \%)$ & $4(13 \%)$ \\
\hline $70+$ & $21(5 \%)$ & 0 \\
\hline \multicolumn{3}{|l|}{ BIRADS } \\
\hline $0,1,2$ & $23(6 \%)$ & $18(60 \%)$ \\
\hline 3 & $203(50 \%)$ & $7(23.3 \%)$ \\
\hline $4,5,6$ & $162(40 \%)$ & $4(13.3 \%)$ \\
\hline unknown & $14(3 \%)$ & $1(3.3 \%)$ \\
\hline \multicolumn{3}{|l|}{ Tumor stage } \\
\hline । & $85(21 \%)$ & $2(7 \%)$ \\
\hline$\|$ & $122(30 \%)$ & $12(40 \%)$ \\
\hline III & $84(21 \%)$ & $12(40 \%)$ \\
\hline IV & $19(5 \%)$ & $3(10 \%)$ \\
\hline unknown & $92(23 \%)$ & $1(3 \%)$ \\
\hline Patients without IHC testing & $372(93 \%)$ & 0 \\
\hline Patients with $\mathrm{IHC}$ testing & $30(7 \%)$ & $30(100 \%)$ \\
\hline \multicolumn{3}{|l|}{ ER testing } \\
\hline positive & n.a. & $17(57 \%)$ \\
\hline negative & & $11(37 \%)$ \\
\hline unknown & & $2(7 \%)$ \\
\hline \multicolumn{3}{|l|}{ PR testing } \\
\hline positive & n.a. & $16(53 \%)$ \\
\hline negative & & $12(40 \%)$ \\
\hline unknown & & $2(7 \%)$ \\
\hline \multicolumn{3}{|l|}{ HER2 testing } \\
\hline positive & n.a. & $5(17 \%)$ \\
\hline negative & & $23(77 \%)$ \\
\hline unknown & & $2(7 \%)$ \\
\hline \multicolumn{3}{|l|}{ Additional IHC testing } \\
\hline Ki67, P53 & n.a. & $1(3 \%)$ \\
\hline unknown & & $29(97 \%)$ \\
\hline \multicolumn{3}{|c|}{ Subtype according to the Mexican Consensus [4] } \\
\hline Luminal A & n.a. & $14(47 \%)$ \\
\hline Luminal B & & $3(10 \%)$ \\
\hline Basal-like/Triple negative & & $9(30 \%)$ \\
\hline HER2 & & $2(7 \%)$ \\
\hline not enough information to assign & & $2(7 \%)$ \\
\hline
\end{tabular}

block HER2 (e.g. trastuzumab or pertuzumab). The use of in situ hybridization (ISH), instead of IHC, can be used to determine HER2 status with an overall concordance with IHC, and it may be more beneficial to use both [19]. Furthermore, HER2 status has been successfully incorporated into medical practice to guide treatment decisions for breast cancer patients. In fact, the American Society of Clinical Oncology/College of American Pathologists (ASCO/CAP) updated their 2013 guidelines to designate more patients as eligible for trastuzumab therapy, in accordance with ISH and IHC testing [20]. Also, the BHGI resource stratified guidelines recommend the use of trastuzumab at the enhanced level due to the high cost of the drug, as well as for the availability for testing. The IMSS's medications chart [21] reports trastuzumab as an available drug for any HER+ positive patient in the country.

\section{On the timeliness of IHC testing}

Opportune IHC testing, understood as the availability of IHC results before the beginning of any treatment, is of critical importance. For the IMSS hospital in this study, IHC results were typically not timely opportune, but whenever they were available they triggered a response from the clinical oncology team to adjust patient treatments. The wide dispersion of time to request and turnaround time demonstrates the lack of standardization of this process. Many factors could have contributed to the delay in IHC testing, including: patient non-adherence to appointments; hospital overflow, resulting in delayed appointments; logistical problems between IMSS and the external laboratory service; and administrative problems within the hospital resulting in inadequate tracking of tests and results.

It is important to establish an appropriate timeline for opportune IHC testing. For example, In the United States, the College of American Pathologists' (CAP) guideline on turnaround time for biopsy testing is around two days for $90 \%$ of cases [22]. In fact, the joint guideline on HER2 testing from the American Society of Clinical Oncology (ASCO) and CAP recommends informing the patients about the expected turnaround time [23]. In Australia, a study revealed that the average turnaround time was between 4 and 5 days [24]. In Saudi Arabia, a study showed that $24 \%$ of cases fall outside the recommended CAP turnaround time [25]. The European Society for Medical Oncology (ESMO) published a survey on 24 European countries were the turnaround time was 10 days or less for $89 \%$ of laboratories [26]. In the United Kingdom, the Royal College of Pathologists recommend the use of key performance indicators to 


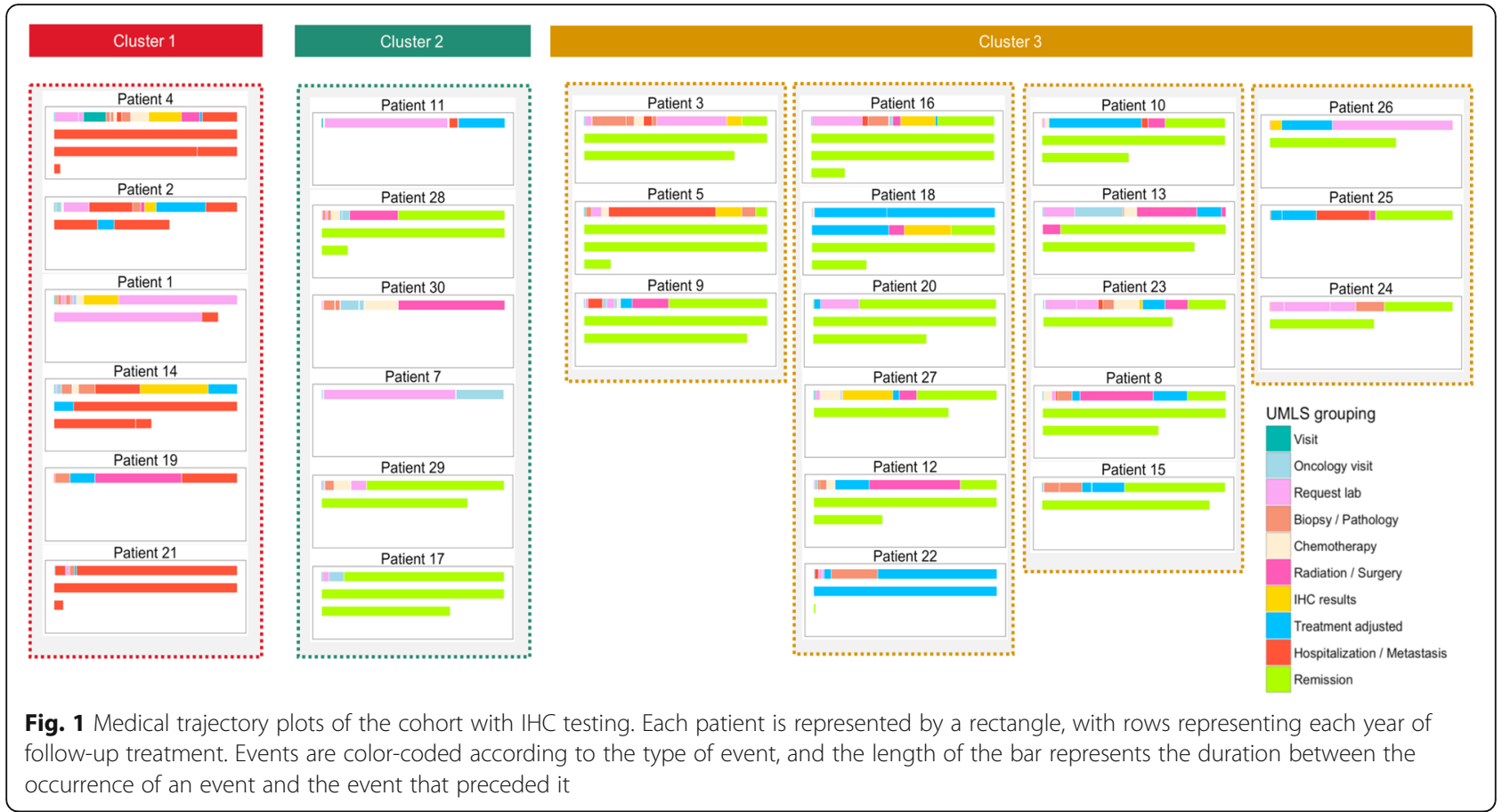

have a histopathology diagnosis within seven days of biopsy in $90 \%$ of cases [27].

Given their resource-available settings, clinical guidelines in developed countries do not have a recommendation regarding the maximum turnaround time that could be effective in a patient's treatment trajectory. More importantly, they do not address the time between initial diagnosis, molecular testing, and the selection of treatment. In Mexico, clinical guidelines for breast cancer recommend testing for ER, PR, and HER2 as part of the histopathology study, but fail to provide guidance regarding turnaround time. IMSS maintains a medical procedures manual, which includes ten key indicators for breast cancer screening, diagnosis, and treatment [28]. This manual measures time-to-diagnosis in a 30-day period, including imaging through mammography and results of histopathology report. In addition, the institution also measures time-to-treatment measured from the date of diagnosis, which should be achieved within a 21-day period. Recognizing the resource constraints of IMSS, the implementation of a key indicator policy related to IHC testing might significantly reduce turnaround times.

\section{On the need to monitor the percentage of patients being tested}

The monitor shown in Fig. 1 quickly provides a patient history overview of hospital care, while Fig. 2 shows the detailed information for turnaround time. With more work on the user interface, we envision a tool that could eventually represent a valuable visual aid for hospital administrators, providing a quick overview of the patients seen in their hospital, which could be used as a decision-making tool, with the proper validation.

The low percentage $(7.4 \%)$ of patients observed to be tested requires special attention. A common concern of retrospective chart review studies is underreporting. The amount of recorded information in the hospital included in our study can be improved by providing training to the clinical and administrative staff about the importance of requesting and reporting IHC testing. In the absence of a cancer registry, our best estimate of the disease is the institutional census, which does not record IHC testing results. As the hospitals in Mexico, and elsewhere, continue to become more and more electronic, there is a need to develop better software tools to facilitate recording and analyzing clinical information, including medical natural language processing and machine learning applications.

\section{Conclusions}

Adverse events in the trajectory of an oncological patient, which might include hospitalization related to cancer, recurrence of tumor, or metastasis, are extremely costly for the healthcare system. The use of IHC testing was shown in our study to help with the selection of precise treatment for patients (either by adjusting the treatment or confirming it). The time in which IHC 


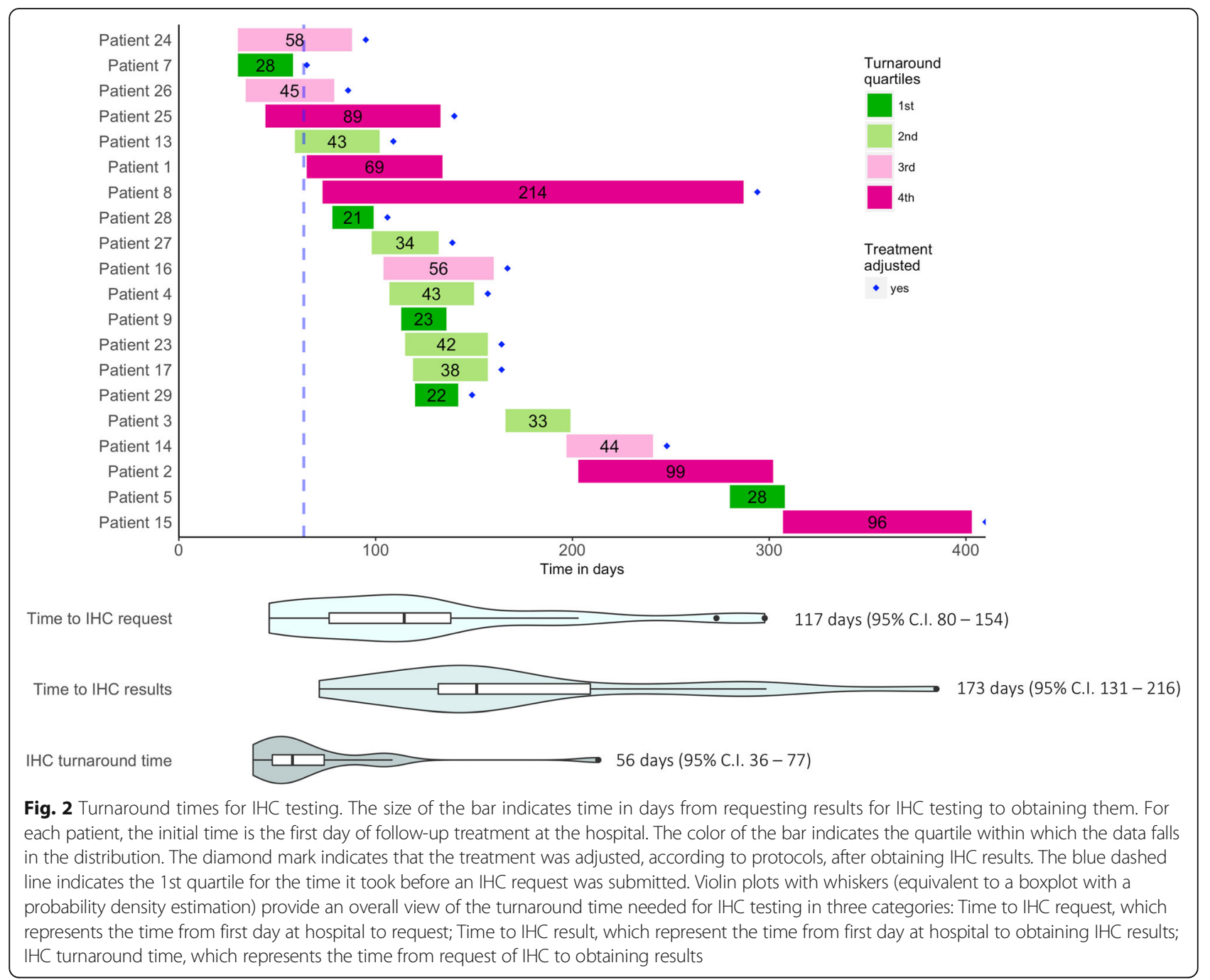

testing is performed is of critical importance if we want to influence improved prognosis.

We have revealed in this cohort that the use of opportune IHC testing is associated with beneficial therapeutic effects on breast cancer patients. The aims of any healthcare system should be the identification of earlier events that can have an impact on downstream events in the trajectory of an oncological patient's treatment. In resource-constrained settings, it is important not only to consider alternatives to more costly diagnostics (e.g. genomic testing), but also to incorporate the regulatory and logistical aspects of implementing these tests.

IMSS must face the important challenge of continuing to improve their turnaround times, which should have a positive impact on the prognosis of their patients. As the Mexican healthcare system continues to transition from reactive to preventative care, the need for more IHC testing in breast cancer and other diseases will certainly allow for the further development of digital patient monitoring.

\section{Additional files}

Additional file 1: STROBE Statement Checklist. (PDF $98 \mathrm{~kb}$ )

Additional file 2: Clustering analysis. (PDF $760 \mathrm{~kb}$ )

Additional file 3: Spanish translation. (PDF $675 \mathrm{~kb}$ )

\section{Acknowledgements}

The authors wish to acknowledge Katie Kanagawa, PhD, for her valuable support in editing this manuscript.

\section{Funding}

Research reported in this publication was partially supported via institutional funds from each individual researcher institution, either the Mexican Institute of Social Security (IMSS) or Stanford University. In addition, ALP and CDB were partially supported by the following grants: U01 HG007436-04 from the National Human Genome Research Institute (NHGRI)'s Clinically Relevant Genome Variation Database; and U01 FD004979 from the Food and Drug Administration (FDA)'s joint Center of Excellence in Regulatory Science and Innovation (CERSI) at the University of California, San Francisco and Stanford University. The funders had no role in study design, data collection and analysis, decision to publish, or preparation of the manuscript. 


\section{Availability of data and materials}

Data belongs to the Mexican Institute of Social Security (IMSS), through its state Delegation of Michoacan. IMSS's Coordination of Health Research may grant access to this data on a case-by-case basis to researchers who obtain the necessary approvals from IMSS's National Scientific Research Committee and National Bioethics Committee.

\section{Authors' contributions}

ALP designed the study. MFRM reviewed medical notes. MFRM and ALP performed the analysis of the data. ASB, SNS, RAR, CAA, SMFV and CDB provided interpretation of the results. Translations. The present manuscript was translated into Spanish by bilingual co-author ALP. The translated manuscript is provided in Additional file 3. ALP drafted the manuscript, and all authors contributed critically, read, revised and approved the final version.

\section{Ethics approval and consent to participate}

This research was reviewed and approved by the Mexican Institute of Social Security (IMSS)'s National Scientific Research Committee and its National Bioethics Committee, under protocol number R-2017-785-010, and locally by IMSS' Local Research and Ethics Committee, under specific protocol number R-2017-1602-14 HGR1 Charo, Michoacan. Stanford's Institutional Review Board provided a non-human subject determination under eProtocol: 40704. Researchers only received access to non-identifiable data under the considerations of the applicable Mexican bylaws on health research, patient privacy, and electronic medical records. Consent was not required.

\section{Consent for publication}

Not applicable.

\section{Competing interests}

RAR declares to be IMSS's state delegate in Michoacan, overseeing the hospital mentioned in this study. The authors declare that they have no competing interests.

\section{Publisher's Note}

Springer Nature remains neutral with regard to jurisdictional claims in published maps and institutional affiliations.

\section{Author details}

'Department of Biomedical Data Science, School of Medicine, Stanford University, 1265 Welch Road, Stanford, California 94305, USA. ${ }^{2}$ Facultad de Ciencias Médicas y Biológicas "Dr. Ignacio Chávez", Universidad Michoacana de San Nicolás de Hidalgo, Av. Dr. Rafael Carrillo S/N, Esq. Dr. Salvador González Herrejón, Morelia 58020, Michoacán, Mexico. ${ }^{3}$ Coordinación de Investigación en Salud, Delegación Michoacán, Instituto Mexicano del Seguro Social, Av. Madero Poniente No. 1200, Morelia 58000, Michoacán, Mexico. ${ }^{4}$ Hospital General Regional No. 1, Servicio de Ginecobstetricia, Instituto Mexicano del Seguro Social, Bosques de los Olivos No. 101, Charo 61303, Michoacán, Mexico. ${ }^{5}$ Delegación Michoacán, Instituto Mexicano del Seguro Social, Av. Madero Poniente No. 1200, Morelia 58000, Michoacán, Mexico. ${ }^{6}$ Department of Genetics, School of Medicine, Stanford University, 300 Pasteur Drive, Stanford 94305, California, USA. ${ }^{7}$ Department of Medicine (Hematology), School of Medicine, Stanford University, 875 Blake Wilbur Drive, Stanford 94305 , California, USA. ${ }^{8}$ Department of Medicine (Oncology), School of Medicine, Stanford University, 875 Blake Wilbur Drive, Stanford 94305, California, USA.

Received: 25 February 2018 Accepted: 18 September 2018

\section{Published online: 27 September 2018}

\section{References}

1. Lips EH, Mulder L, de Ronde JJ, IAM M, Koolen BB, LFA W, et al. Breast cancer subtyping by immunohistochemistry and histological grade outperforms breast cancer intrinsic subtypes in predicting neoadjuvant chemotherapy response. Breast Cancer Res Treat Springer US. 2013;140:63-71.

2. Won JR, Gao D, Chow C, Cheng J, Lau SYH, Ellis MJ, et al. A survey of immunohistochemical biomarkers for basal-like breast cancer against gene expression profile gold standard. Mod Pathol. 2013;26:1438-50.

3. Abu-Khalf M, Pusztai L. Influence of genomics on adjuvant treatments for pre-invasive and invasive breast cancer. Breast. 2013;22(Suppl 2):S83-7.
4. Cardenas Sanchez J, Rocha JEB, Piña VB, Sánchez GC, Erazo Valle-Solís AA, Balcázar CHF, et al. Mexican Consensus on the Diagnosis and Treatment of Breast Cancer: Seventh Revision - Colima 2017. Gaceta Mexicana de Oncología. 2017:16:7-78.

5. Secretaria de Salud de Mexico. Diagnóstico y Tratamiento de la Patología Mamaria Benigna en Primer y Segundo Nivel de Atención; 2009. p. 1-66.

6. Secretaria de Salud de Mexico. Prevención, Tamizaje y Referencia Oportuna de Casos Sospechosos de Cáncer de Mama en el Primer Nivel de Anteción; 2011. p. 1-74.

7. Secretaria de Salud de Mexico. Diagnóstico y Tratamiento del Cáncer de Mama en Segundo y Tercer Nivel de Atención; 2012. p. 1-102.

8. Lara-Medina F, Perez-Sanchez V, Saavedra-Perez D, Blake-Cerda M, Arce C, Motola-Kuba D, et al. Triple-negative breast cancer in Hispanic patients: high prevalence, poor prognosis, and association with menopausal status, body mass index, and parity. Cancer. 2011;117:3658-69.

9. Robles-Castillo J, Ruvalcaba-Limón E. Ginecologia y Obstetricia de Mexico. In: Cáncer de mama en mujeres mexicanas menores de 40 años, vol. 79; 2011. p. 482-8.

10. Villarreal-Garza C, Alvarez-Gomez RM, Perez-Plasencia C, Herrera LA, Herzog J, Castillo D, et al. Significant clinical impact of recurrent BRCA1 and BRCA2 mutations in Mexico. Cancer. 2015;121:372-8.

11. Mohar-Betancourt A, Reynoso-Noveron N, Armas-Texta D, Gutierrez-Delgado C, Torres-Dominguez JA. Cancer trends in Mexico: essential data for the creation and follow-up of public policies. J Glob Oncol 2017; JGO.2016.007476-9.

12. Shaaban AM, Purdie CA, Bartlett JMS, Stein RC, Lane S, Francis A, et al. HER2 testing for breast carcinoma: recommendations for rapid diagnostic pathways in clinical practice. J Clin Pathol; BMJ Publishing Group. 2014;67:161-7.

13. Anderson BO, Yip C-H, Smith RA, Shyyan R, Sener SF, Eniu A, et al. Guideline implementation for breast healthcare in low-income and middle-income countries: overview of the breast health global initiative global summit 2007. Cancer Wiley Subscription Services, Inc., A Wiley Company; 2008. pp. 2221-2243.

14. Carlson RW, Scavone JL, Koh W-J, McClure JS, Greer BE, Kumar R, et al. NCCN framework for resource stratification: a framework for providing and improving global quality oncology care. J Natl Compr Cancer Netw. 2016;14:961-9.

15. Chuang LT, Temin S, Berek JS. Management and Care of Women with Invasive Cervical Cancer: American Society of Clinical Oncology resourcestratified clinical practice guideline summary. J Oncol Pract. 2016;12:693-6.

16. World Health Organization. Executive summary. National Cancer Control Programmes. Policies and Managerial Guidelines. 2012:1-24.

17. Instituto Nacional de Estadística y Geografía. [Encuesta Intercensal 2015]. 2015.

18. Instituto Mexicano para la Competitividad. Indice de Competitividad Estatal 2016; 2016. p. 1-202

19. Solomon JP, Dell'Aquila M, Fadare O, Hasteh F. Her2/neu status determination in breast Cancer. A Single Institutional Experience Using a Dual-Testing Approach With Immunohistochemistry and Fluorescence In Situ Hybridization Am J Clin Pathol. 2017;147:432-7.

20. Lim TH, Lim AST, Thike AA, Tien SL, Tan PH. Implications of the updated 2013 American Society of Clinical Oncology/College of American Pathologists Guideline Recommendations on human epidermal growth factor receptor 2 gene testing using immunohistochemistry and fluorescence in situ hybridization for breast Cancer. Arch Pathol Lab Med. 2016;140:140-7.

21. Instituto Mexicano del Seguro Social. [Cuadro Basico de Medicamentos. Oncologia] Instituto Mexicano del Seguro Social; 2017. p. 1-48.

22. Novis DA, Zarbo RJ, Saladino AJ. Interinstitutional comparison of surgical biopsy diagnosis turnaround time: a College of American Pathologists Qprobes study of 5384 surgical biopsies in 157 small hospitals. Arch Pathol Lab Med. 1998;122:951-6.

23. Wolff AC, Hammond MEH, Hicks DG, Dowsett M, McShane LM, Allison KH, et al, Recommendations for human epidermal growth factor receptor 2 testing in breast Cancer: American Society of Clinical Oncology/College of American Pathologists Clinical Practice Guideline Update. J Clin Oncol. 2013;31:3997-4013.

24. Morey AL, Brown B, Farshid G, Fox SB, Francis GD, McCue G, et al. Determining HER2 (ERBB2) amplification status in women with breast cancer: final results from the Australian in situ hybridisation program. Pathology Elsevier; 2016;48:535-542.

25. Alshieban S, Al-Surimi K. Reducing turnaround time of surgical pathology reports in pathology and laboratory medicine departments. BMJ Qual Improv Rep BMJ Open Quality; 2015;4:u209223.w3773. 
26. Boleij A, Tembuyser L, Taylor A, Kafatos G, Jenkins-Anderson S, Tack V, et al. PD-015A survey on current RAS-mutation testing practices in Europe. Ann Oncol Oxford University Press. 2015;26:iv105-5.

27. Pathologists TRCO. Key Performance Indicators in Pathology; 2013. p. 1-23.

28. Instituto Mexicano del Seguro Social. Manual Metodológico de Indicadores Médicos 2016; 2016. p. 1-452.

Ready to submit your research? Choose BMC and benefit from:

- fast, convenient online submission

- thorough peer review by experienced researchers in your field

- rapid publication on acceptance

- support for research data, including large and complex data types

- gold Open Access which fosters wider collaboration and increased citations

- maximum visibility for your research: over $100 \mathrm{M}$ website views per year

At BMC, research is always in progress.

Learn more biomedcentral.com/submissions 